\title{
Identifying Prognostic Factors for Well-Differentiated Metastatic Pancreatic Neuroendocrine Tumours: A Retrospective International Multicentre Cohort Study
}

\author{
Paula Jiménez-Fonseca ${ }^{a}$ Sebastian Krug $^{\text {b }}$ Gianluca Tamagno ${ }^{c}$ \\ Felipe Fierro Maya $^{d}$ Antonio Monléon Getino ${ }^{\mathrm{e}}$ Clara Isabel Rodriguez Casado ${ }^{\mathrm{e}}$ \\ Frederico Costa $^{f}$ Wouter W. de Herder ${ }^{g}$ Henning Jann ${ }^{\text {h }}$ \\ ${ }^{a}$ Hospital Universitario Central de Asturias, Oviedo, Spain; ${ }^{b}$ Martin Luther Universität, Halle (Saale), Germany; \\ 'Mater Misericordiae University Hospital, Dublin, Ireland; ' Instituto Nacional de Cancerologia, Bogota, Colombia; \\ e Universitat de Barcelona, Barcelona, Spain; ${ }^{\mathrm{f} H}$ ospital Sirio-Libanes, Sao Paulo, Brazil; ${ }^{9}$ Erasmus Medical Center, \\ Rotterdam, The Netherlands; ${ }^{\text {h } C h a r i t e ́, ~ U n i v e r s i t a ̈ t s m e d i z i n ~ B e r l i n, ~ B e r l i n, ~ G e r m a n y ~}$
}

\section{Keywords}

Biomarkers · Cohort study · Multivariate analysis · Overall survival · Pancreatic neuroendocrine tumours - Prognostic factors

\begin{abstract}
Pancreatic neuroendocrine tumours (pNETs) represent rare neoplasms of all NETs often presenting without functional activity. Many sporadic non-functioning PNET patients are already metastatic at the time of diagnosis, and the therapeutic approach to such patients is mostly palliative. In this international, multicentre, retrospective cohort study, we assessed the prognostic value of a set of anthropometric, clinical, biochemical, radiological and pathological parameters at baseline and the impact of the therapeutic strategies on the survival of patients with sporadic grade 1/2, stage IV, non-functioning pNETs. Three hundred and twelve consecutive patients diagnosed between 1993 and 2010 were included. The median overall survival (OS) was 6.6 years and survival at 5 and 10 years was 62 and 34\% respectively. On
\end{abstract}

() 2018 S. Karger AG, Basel

E-Mail karger@karger.com www.karger.com/nen univariate analysis, Eastern Cooperative Oncology Group (ECOG) status $\geq 2$, grade 2, bilobar hepatic metastases, synchronous metastases, and high chromogranin A, alkalinephosphatase and lactic-dehydrogenase were associated with a significant reduction of OS. Palliative/curative surgery and loco-regional hepatic interventions were significant factors improving OS. On multivariate analysis, ECOG status $\geq 2$, synchronous metastases, Ki- $67 \geq 10 \%$, and high alkalinephosphatase correlated significantly with an increased risk of death. Both palliative/curative surgery and loco-regional hepatic interventions had a positive impact on OS. Although most parameters did not prove to be independent OS predictors at multivariate analysis, they showed a tendency towards that. Future prospective studies including larger patient populations may give greater clarity. We believe the integration of these parameters has the potential to provide a reliable prognostic score for the stratification of patients with sporadic well-differentiated metastatic non-functioning pNETs.

(c) 2018 S. Karger AG, Basel

All authors contributed equally to this work. 


\section{Introduction}

Pancreatic neuroendocrine tumours (pNETs) are rare neoplasms accounting for about $2-5 \%$ of all pancreatic tumours [1-3]. These tumours are characterized by clinical and behavioural heterogeneity, with roughly 60-90\% of them presenting without hormone hypersecretion syndrome and being defined as non-functioning pNETs [4, 5]. Also, due to their often-indolent clinical manifestations, a large number of non-functioning pNET patients present with metastatic disease at the time of diagnosis. The majority of pNETs are sporadic; however, they may also occur in the setting of various inherited syndromes, including multiple endocrine neoplasia type 1, Von Hippel-Lindau disease, neurofibromatosis type 1 , and tuberous sclerosis [6]. While pNETs associated with familial syndromes are usually more indolent than their sporadic counterparts, pNET patients with an inherited disease are at higher risk of developing multifocal tumours and, consequently, require different therapeutic and follow-up strategies [6]. Despite the high rate of liver metastases at the time of the diagnosis, non-functioning pNETs are associated with a more favourable prognosis compared to most gastrointestinal malignancies and the overall survival at 5 years (5yOS) is estimated to be around $30-60 \%$, depending on the centre treated $[1,2,7]$.

The therapeutic approaches currently available for the treatment of metastatic pNETs are different from curative surgery, primary tumour resection or palliative strategies to control symptoms and, possibly, improve patient survival $[8,9]$. In a study on patients with a metastatic pNET, an aggressive therapeutic strategy appeared to be associated with more favourable outcomes, with a median OS of 4.8 years in patients who underwent aggressive surgery versus 1 year in those who did not undergo resection [1]. However, only a small proportion of patients with metastatic non-functioning pNETs are suitable candidates for surgical resection of their primary tumour or liver metastases, and this may significantly affect the overall prognosis of pNET patients. A careful multidisciplinary evaluation of patients can help identify those who are more likely to benefit from an aggressive therapeutic approach with regard to OS $[4,10]$. However, in other studies, and in an extensive review of the literature, less clear conclusions have been drawn and the value of an aggressive rather than conservative therapeutic approach still appears to be undefined $[11,12]$. In practice, the prognosis of pNET patients cannot be easily predicted and opting for a more conservative strategy, including a wait-and-see approach, rather than aggressive manage- ment is still a matter of debate among the experts [9]. Some decision-making aids have been entitled comprising tumour load, proliferation index, rapid tumour progress and symptomatic disease [7]. However, there are no unequivocal data in the literature indicating which laboratory measures, radiological features, or patient characteristics may be reliable prognostic factors and able to direct therapeutic decisions. Recently, a prognostic model based on mitotic rate and functional status has been shown to correlate with pNET patient OS [13]. In patients who underwent surgery, high pre-operative chromogranin A ( CgA) was negatively associated with diseasefree survival and OS and appeared to be the only independent predictor of disease-free survival in that cohort of patients [14]. The validity of $\mathrm{CgA}$ as a prognostic tool was also reported in a study from China on a series of patients with non-functioning pNETs and liver metastases [15]. As predictors of survival, both the American Joint Committee on Cancer and the European Neuroendocrine Tumor Society (ENETS) TNM- classification appear to have a prognostic value in different patient populations $[16$, 17]. In a study from Italy, the OS of gastroenteropancreatic NET patients after resection of the primary tumour correlated with both patient age and World Health Organization (WHO) 2010 staging (which strongly depends on Ki-67 proliferation index), but not with the site of the primary tumour [18]. A retrospective study from Norway involving 114 patients with well-differentiated pNETs showed that Ki-67 $>2 \%$, high CgA levels, presence of distant metastases and palliative treatment were associated with poor OS [19].

In this international, multicentre, retrospective cohort study, we have evaluated the prognostic value of a set of baseline anthropometric, clinical, biochemical, radiological and pathological parameters and the impact of the treatment modalities on the survival of patients with sporadic well-differentiated metastatic non-functioning pNETs, with the goal of building up a clinical risk stratification tool for prognostic assessment.

\section{Materials and Methods}

\section{Study Design}

The inclusion criteria were pathologically confirmed well-differentiated, grade 1 or 2 (Ki-67 index $\leq 20 \%$ ), advanced pNETs and metastatic disease (stage IV) diagnosed between 01 January 1993 and 01 January 2010. The minimum follow-up period was 5 years. Familial and syndromic pNETs were excluded (e.g., multiple endocrine neoplasia type 1), as well as those with secondary malignancy. This study has been carried out in accordance with the principles of the Declaration of Helsinki. 


\section{Variables}

Data collected included demographics (name of centre, age at diagnosis, gender, Eastern Cooperative Oncology Group performance status [ECOG-PS], date of initial diagnosis, date of diagnosis of metastatic disease); clinical presentation (primary tumour site [head, body, tail of pancreas], site of metastases, location of hepatic metastases according to liver lobes [right, left or both lobes], functionality, type of functionality, synchronous versus metachronous metastases, Ki-67 and mitotic index); laboratory parameters (bilirubin, alkaline phosphatase [AP], lactate dehydrogenase [LDH], albumin, creatinine, CgA]); treatment and date of last follow-up or death. Synchronous metastasis was defined as occurring within the first year after initial diagnosis. The exact date of diagnosis of metastatic disease was correlated with the first imaging study giving evidence of metastatic spread. Data on Ki-67 was obtained from the time of initial diagnosis; in case of metachronous metastases the most current Ki67 data was used. Therapeutic interventions included surgery, systemic treatment and loco-regional hepatic therapy. Surgery was defined as curative when all of the primary tumour and metastases were removed (R0-Status), or as palliative (R1- or R2-Status). Surgical therapy included both operation and radiofrequency ablation. Systemic treatment involved medical therapy (somatostatin analogues, chemotherapy and molecular-targeted therapy) and peptide receptor radionuclide therapy (PRRT). Loco-regional therapy included transarterial embolization, transarterial chemoembolization and selective internal radiation therapy. Laboratory parameters were documented closest to the date of diagnosis of metastatic disease. For each laboratory parameter, data collected were: absolute value, normal range and the category (normal or elevated).

\section{Outcomes and Statistical Methods}

The association of categorical variables was assessed by the chi square test or Fisher's exact test. Continuous variables were expressed as medians with ranges. Outcomes calculated were OS, 1, 5 and 10yOS. OS was calculated as the time elapsed from the date of diagnosis of metastatic disease to the date of death or last follow-up in living patients. Five and $10 \mathrm{yOS}$ was the percentage of patients who were alive 5 and 10 years, respectively, after the diagnosis of metastatic disease. Survival was estimated according to the Kaplan-Meier product limit method accompanied by the 95\% CI. Comparisons between OS for levels of the relevant clinical covariates were performed using the log-rank test. A $p$ value of $<0.05$ was considered statistically significant. Univariate and multivariate analyses using the Cox proportional hazards model were carried out to identify covariates independently associated with prognosis. The CIs for the regression coefficients were based on the Wald statistic. Only variables with a $p$ value of $<0.10$ at univariate analysis were introduced in the Cox model. Relative risks were expressed as hazard ratios (HR) with corresponding $p$ values. All statistical analyses were performed using $\mathrm{R}$ version 3.2.3 (The R Foundation for Statistical Computing platform).

\section{Results}

This was a retrospective, international, multicentre study on prognostic parameters in patients with well-differentiated, metastatic pNETs. The present study involved 6 tertiary referral centres from Germany, Ireland,
Table 1. Characteristics of patients, tumours and treatments

\begin{tabular}{|c|c|c|}
\hline Characteristic & $n$ & $\%$ \\
\hline Gender, male & 180 & 57.69 \\
\hline Age, $>50$ years & 204 & 65.38 \\
\hline $\mathrm{ECOG}^{*} \mathrm{PS}, \geq 2$ & 20 & 6.41 \\
\hline \multicolumn{3}{|l|}{ Histological grade } \\
\hline Grade 1 & 99 & 31.73 \\
\hline Grade 2 & 202 & 64.74 \\
\hline Not reported/missing & 11 & 3.53 \\
\hline \multicolumn{3}{|c|}{ Synchronous and metachronous metastases } \\
\hline Metachronous & 26 & 8.33 \\
\hline Synchronous & 276 & 88.46 \\
\hline Missing & 10 & 3.21 \\
\hline \multicolumn{3}{|l|}{ Hepatic metastases } \\
\hline Right lobe & 21 & 6.73 \\
\hline Left lobe & 19 & 6.09 \\
\hline Both lobes & 215 & 68.91 \\
\hline Not reported/missing & 57 & 18.27 \\
\hline \multicolumn{3}{|l|}{ Extra-hepatic metastases } \\
\hline Lymph nodes & 91 & 29.2 \\
\hline Others & 103 & 33.0 \\
\hline Non-existent & 77 & 24.7 \\
\hline Missing & 41 & 13.1 \\
\hline \multicolumn{3}{|l|}{ Surgery } \\
\hline Yes & 129 & 41.35 \\
\hline Curative intention & 33 & 10.6 \\
\hline Palliative intention & 96 & 30.8 \\
\hline No & 140 & 44.87 \\
\hline Not reported/missing & 43 & 13.78 \\
\hline \multicolumn{3}{|l|}{ Systemic intervention } \\
\hline Yes & 249 & 79.81 \\
\hline No & 21 & 6.73 \\
\hline Not reported/missing & 42 & 13.46 \\
\hline \multicolumn{3}{|l|}{ Loco-regional treatment } \\
\hline Yes & 47 & 15.06 \\
\hline No & 221 & 70.83 \\
\hline Not reported/missing & 44 & 14.1 \\
\hline \multicolumn{3}{|l|}{ Baseline CgA } \\
\hline Normal & 46 & 14.74 \\
\hline Elevated & 175 & 56.09 \\
\hline Missing & 91 & 29.16 \\
\hline \multicolumn{3}{|l|}{ Baseline AP } \\
\hline Normal & 153 & 49.04 \\
\hline Elevated & 76 & 24.36 \\
\hline Missing & 83 & 26.6 \\
\hline \multicolumn{3}{|l|}{ Baseline LDH } \\
\hline Normal & 158 & 50.64 \\
\hline Elevated & 55 & 17.63 \\
\hline Missing & 99 & 31.73 \\
\hline \multicolumn{3}{|l|}{ Baseline bilirubin } \\
\hline Normal & 178 & 57.05 \\
\hline Elevated & 44 & 14.10 \\
\hline Missing & 90 & 28.85 \\
\hline \multicolumn{3}{|l|}{ Baseline creatinine } \\
\hline Normal & 203 & 65.06 \\
\hline Elevated & 19 & 6.09 \\
\hline Missing & 90 & 28.85 \\
\hline \multicolumn{3}{|l|}{ Baseline albumin } \\
\hline Normal & 205 & 65.71 \\
\hline Decreased & 10 & 3.21 \\
\hline Missing & 97 & 31.09 \\
\hline
\end{tabular}

PS, performance status; CgA, chromogranin A; AP, alkaline phosphatase; LDH, lactate dehydrogenase. * Eastern Cooperative Oncology Group. 
Fig. 1. Median overall, 5 years' and 10 years' survival in metastatic pNET patients. OS, overall survival.

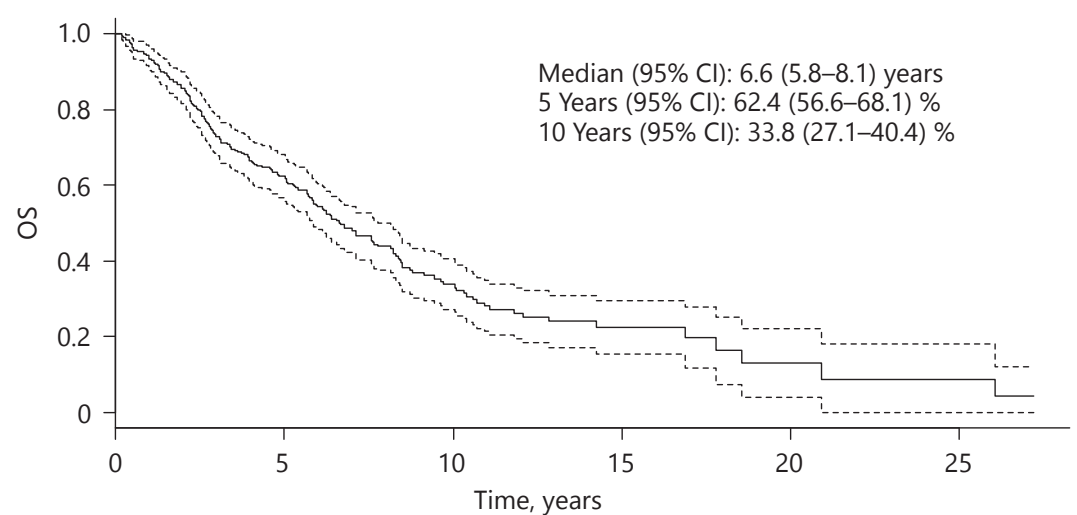

Patients at risk:

285

163

8

5

2

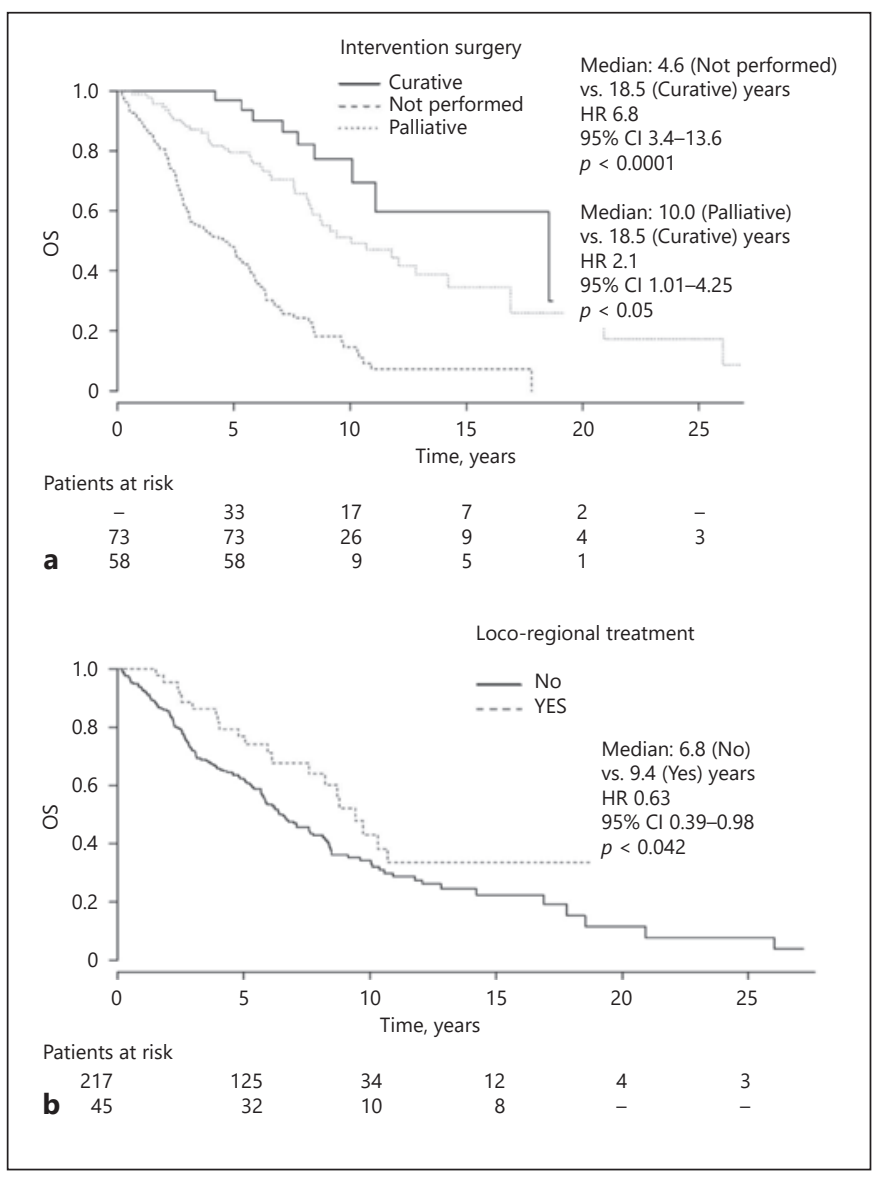

Fig. 2. Therapeutic interventions in pNET patients as significant prognostic factors for survival from univariate analysis. a The median OS was 18.5, 10.0 and 4.6 years for curative surgery, palliative surgery and no surgery groups respectively. b Loco-regional treatment resulted in a significant prolonged OS compared with not performed (median OS 9.4 vs. 6.8 years, HR 0.63, 95\% CI 0.39 $0.98, p<0.042$, Wald test). OS, overall survival.
Spain, the Netherlands, Brazil and Colombia. Patients were identified from hospital records and databases, and were included consecutively from 1993 to 2010. The cutoff date for follow-up was April 1, 2015. A total of 312 metastatic pNET patients met the inclusion criteria. $\mathrm{Pa}$ tient baseline characteristics are shown in Table 1. There were 180 male patients included (58\%), while 204 patients were older than 65 years (65\%). Only a minority presented an ECOG $\geq 2(n=20 ; 6 \%)$ at diagnosis. Most patients revealed a synchronous metastatic disease $(n=276 ; 88 \%)$ with well-differentiated tumours G2 $(n=202 ; 65 \%)$. When assessing hepatic tumour burden, some patients were diagnosed with unilateral liver involvement (7\% right lobe, $6 \%$ left lobe); however approximately two thirds presented with bilobar disease $(n=215 ; 69 \%)$. Beyond liver metastases lymph node involvement was the most common extra-hepatic tumour manifestation $(n=$ 91;29\%). Furthermore, treatment details are listed in Table 1 . One hundred forty patients received no surgery (45\%), but out of 129 patients with surgery 33 patients (11\%) were resected in a curative intent and $96(31 \%)$ in a palliative approach. A systemic intervention including biotherapy, chemotherapy, targeted treatments and PRRT was applied to $80 \%$ of patients $(n=249)$ and locoregional treatment was offered in 47 cases (15\%). Median OS was estimated to be 6.6 years (95\% CI 5.8-8.1; Fig. 1). The proportion of patients who were alive at 5 and 10 years' follow-up was 62 and 34\% respectively.

With univariate Kaplan-Meier analysis, the following variables were associated with a statistically significant reduction in OS: ECOG-PS $\geq 2$ versus $<2$ (median OS: 2.7 vs. 8.5 years, $p<0.0001$ ); grade 2 versus 1 (median OS: 5.7 vs. 9.4 years, $p<0.0001$ ); bilobar compared with uni- 


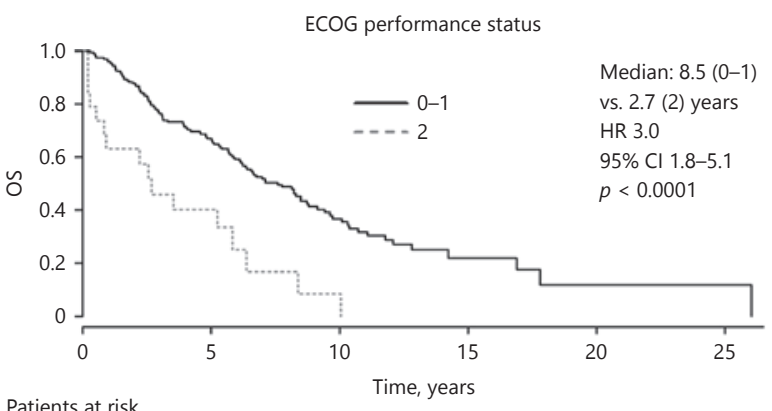

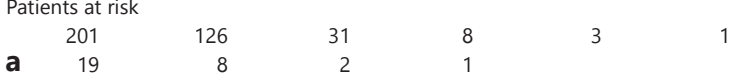

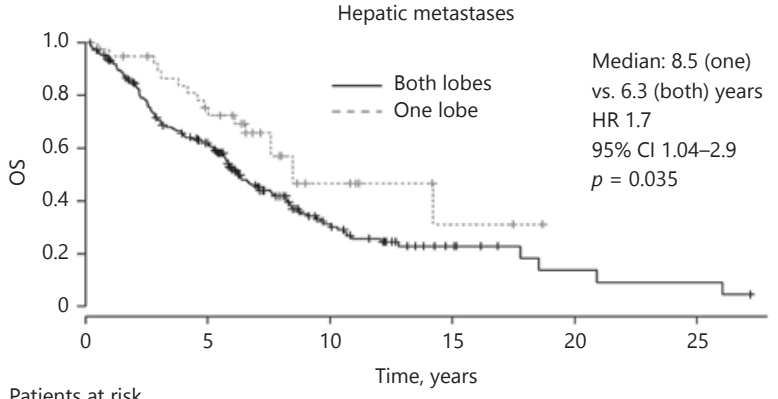

Patients at risk
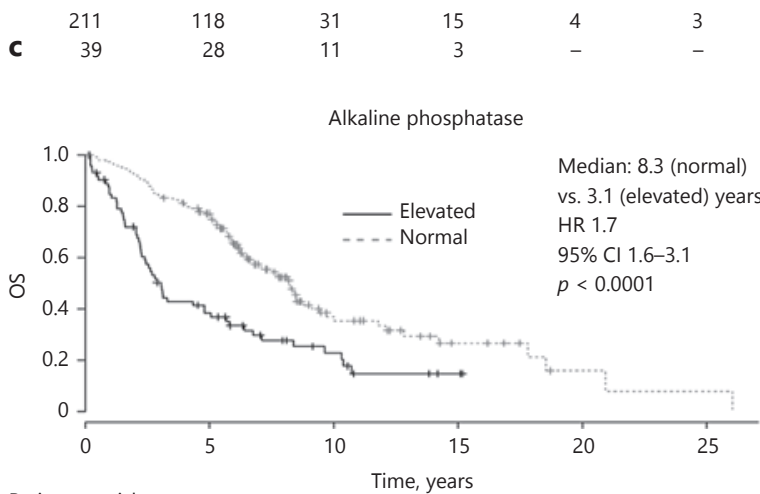

Patients at risk

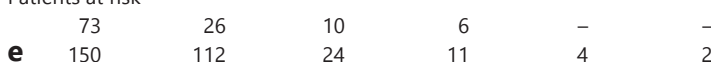

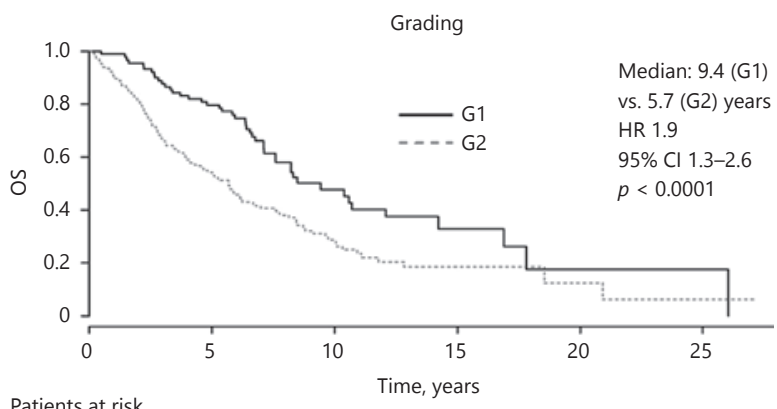

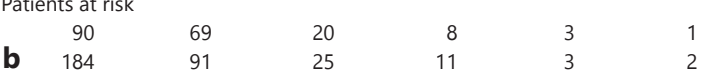
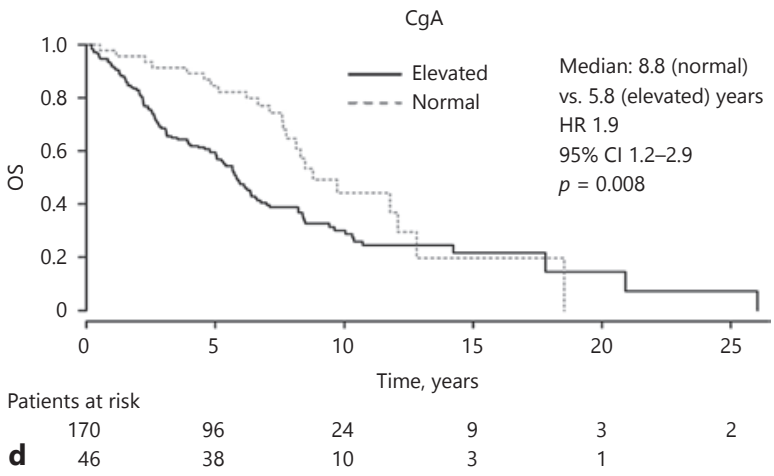

$\mathrm{LDH}$

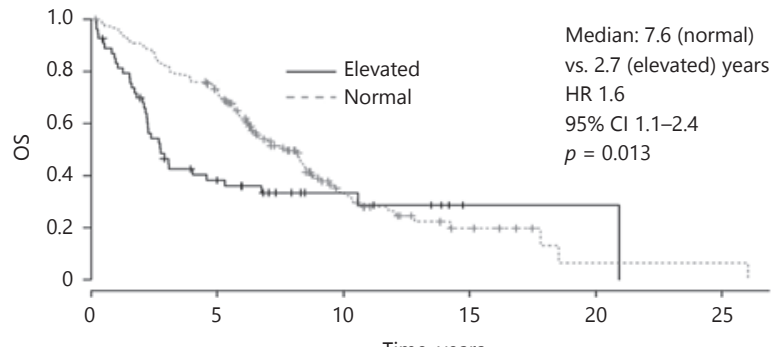

Patients at risk

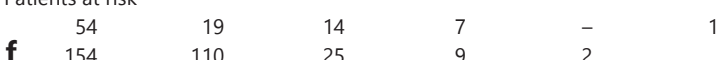

Fig. 3. Selection of different parameters in pNET patients as significant prognostic factors for survival from univariate analysis. a ECOG-PS $\geq 2$ versus $<2$ : the median OS was 2.7 vs. 8.5 years (HR $3.0,95 \%$ CI $1.8-5.1, p<0.0001)$. b Grade 2 versus 1: the median OS was 5.7 vs. 9.4 years (HR 1.9, 95\% CI 1.3-2.6, $p<0.0001$ ). c Hepatic metastases: the median OS was 8.5 years for one lobe compared with 6.3 years for both lobes (HR 1.7, 95\% CI 1.04-2.9, $p=$ 0.035 , Wald test). $\mathbf{d}$ CgA: the median OS was 8.8 years for normal

lobar hepatic metastases (median OS: 6.3 vs. 8.5 years, $p=0.035)$; synchronous vs metachronous metastases (median OS: 5.9 vs. 12.8 years, $p=0.002$ ); elevated versus normal basal CgA (median OS: 5.8 vs. 8.8 years, $p=$ level compared with 5.8 for elevated level (HR 1.9, 95\% CI 1.2-2.9, $p=0.008$, Wald test). e Alkaline Phosphatase: the median OS was 8.3 years for normal level compared with 3.1 for elevated level (HR $1.7,95 \%$ CI 1.6-3.1, $p<0.0001$, Wald test). $f$ LDH: the median OS was 7.6 years for normal level compared with 2.7 for elevated level (HR 1.6, 95\% CI 1.1-2.4, $p=0.013$, Wald test). OS, overall survival; ECOG-PS, Eastern Cooperative Oncology Group performance status. 
Table 2. Mutivariate Cox analysis for factors associated with increase in risk of death

\begin{tabular}{lccc}
\hline Mutivariate Cox analysis & Coefficient & $\mathrm{z}$ & $p$ value \\
\hline ECOG-PS ( $\geq 2$ vs. 0-1) & 0.704127 & 2.503535 & $0.012^{*}$ \\
Metastases (synchronous vs. metachronous) & 0.761831 & 2.093995 & $0.036^{*}$ \\
Histological grade (2 vs. 1) & 0.416900 & 1.813838 & 0.070 \\
Ki-67 index ( $\geq 10 \%$ vs. 1-10\%) & 1.078342 & 4.716314 & $<0.001^{* * *}$ \\
AP (elevated vs. normal) & 0.521302 & 2.538865 & $0.011^{*}$ \\
Loco-regional treatment (yes vs. no) & -0.691276 & -1.935389 & 0.053 \\
Surgical and loco-regional interventions (yes vs. no) & -1.001395 & -3.860232 & $<0.001^{* * *}$ \\
\hline
\end{tabular}

ECOG-PS, Eastern Cooperative Oncology Group performance status; AP, alkaline phosphatase. ${ }^{*} p<0.05$; $* * * p<0.001$.

tention) and loco-regional hepatic interventions as significant prognostic factors (Fig. 2, 3).

Using multivariate Cox analysis, the following variables showed a statistically significant increase in risk of death: ECOG-PS $\geq 2$ (HR 2.02, $p=0.012$ ), synchronous metastases (HR 2.14, $p=0.036$ ); Ki-67 index $\geq 10 \%$ (HR 2.93, $p<0.001)$ and elevated AP (HR 1.68, $p=0.011)$ (Table 2). As far as treatment is concerned, palliative or curative surgery and loco-regional hepatic interventions combined had a significant impact on OS in this cohort of pNET patients.

\section{Discussion}

Prognostic and therapeutic stratification of neuroendocrine tumours is difficult due to the clinical and biological heterogeneity of the disease, as well as due to its rareness $[20,21]$. Over the last decade, several classification systems have been proposed and established, mainly the ENETS TNM classification and grading system, as well as the American Joint Committee on Cancer TNM staging system. These systems have been validated independently and were incorporated in the current UICC/ WHO 2010 classification [16, 22-28]. Other parameters used for prognostic and therapeutic stratification include PS using ECOG has been validated in multiple observational and therapeutic studies as a predictor of outcome.

Functional imaging studies can visualize somatostatin receptor (SSTR)-expression via $\mathrm{Ga}^{68}$-DOTATATE or DOTATOC or DOTANOC PET/CT (Positron Emission Tomography/Computed Tomography), or metabolic activity detected via glucose uptake in ${ }^{18} \mathrm{~F}-\mathrm{FDG}$-PET/CT $\left({ }^{18} \mathrm{~F}-2\right.$-Fluoro-2-Deoxy-D-Glucose-PET/CT) $[29,30]$ as well as the vascularization of the disease, which might permit the patient to undergo local or systemic anti-angiogenic therapy or be treated with somatostatin analogues or PRRT [31-33]. Furthermore, metabolic activity measured via ${ }^{18} \mathrm{~F}-\mathrm{FDG}-\mathrm{PET} / \mathrm{CT}$ can stratify patients into different prognostic subgroups [34].

Biomarkers as well as patient and imaging characteristics are increasingly used in the decision-making process based on their potential prognostic value. In this context, $\mathrm{CgA}$ is well established, but recently published studies have examined the role of circulating tumour cells, microRNAs and multianalyte personalized analyses to understand tumour biology and disease progression [35, 36].

The aim of our multicentre retrospective cohort study was to evaluate metastatic pNET patients to create a stratification tool that can aid the classification of disease prognosis.

In the present study, a median OS of 6.6 years was calculated using Kaplan-Meier analysis, which is similar to that in previous published data $[37,38]$. However, recent retrospective studies with a similarly high percentage of grade 2 tumours ( $~ 65 \%$ in our cohort) have revealed even higher OS rates $[28,39]$. The influence of grading on prognosis is demonstrated in our cohort between grade 1 and grade 2 tumours. With regard to Ki-67 index, we used the established ranges stated in the ENETS-Grading system/WHO 2010 classification [22, 26]. However, there is currently an ongoing scientific discussion on new Ki-67 ranges for pNETs $[28,40,41]$ and our multivariate analyses of the Ki-67 index (cut-off 10\%) showed that it is a strong prognostic marker, and also supports a redefining of the cut-offs. Also with regard to the prognostic impact of the Ki-67 index, it may have some value as a predictive tool, although this was not the aim of our study $[42,43]$. 
Additionally, the biomarker $\mathrm{CgA}$ was shown to significantly affect OS in our cohort. CgA has been used for many decades as a biomarker for neuroendocrine disease activity and it appears to have a dual role. First, CgA is used to define biochemical response under treatment and was correlated with radiological disease response in several studies, thereby emphasizing its predictive impact [44-46]. Second, elevated CgA may reflect hepatic tumour burden, once again a strong prognostic indicator $[45,47]$. In our study cohort, elevated CgA was associated with reduced OS compared with patients who had metastatic disease and normal CgA. However, as a broad-spectrum-marker, CgA has limitations in terms of sensitivity, specificity and reproducibility [36], fuelling ongoing discussion about its usefulness and the merits of new developments in the field [35].

Furthermore, we assessed laboratory values indirectly influenced by the hepatic tumour burden (AP) and cell proliferation (LDH). An elevation of these enzymes was associated with reduced OS. Clancy and colleagues have shown similar results in their publications, where increased levels of AP and LDH were also identified as predictors of earlier death [48].

Regarding the metastatic patterns observed, most patients had hepatic metastases with bilobar involvement, indicative of higher hepatic tumour burden and strongly associated with reduced OS on univariate analysis. Similar associations were seen in the PROMID trial and in a recent study by Panzuto et al. [49, 50]. Those patients who developed metachronous metastases had a favourable HR compared with patients with synchronous metastases. The surgical intervention group also benefitted from significantly longer OS. On univariate analysis, surgery (both with palliative and curative intention) and loco-regional hepatic interventions were identified as significant prognostic factors. Thus, several conclusions may be drawn from this: radical surgical intervention aiming to remove the primary tumour and/or liver metastases or tumour debulking resection can improve the outcome. This supports the conclusions of previous studies on surgical intervention in pNET patients with synchronous liver metastases [51]. Clinically, routine primary tumour resection is often performed to achieve liver-only disease and preselected patients benefit from metastatic resection either with curative or palliative intent. However, this is not validated in prospective and randomized trials and should be critically discussed. Due to the retrospective nature of our study, there may have been a selection bias in which patients who were deemed suitable for surgical therapy usually had a smaller primary, limited metastatic

Identifying Prognostic Factors for pNETs spread and better PS. Essentially, this means that among the group of stage IV patients, this cohort had a better prognosis at the outset. Therefore, it can be assumed that the predominating factor leading to better survival for these patients was the metastatic pattern in a stage IV setting. This hypothesis is supported by several other studies in this area, including the already mentioned series from Panzuto et al. [50], in which 3 distinct subgroups of metastatic pattern were compared. They found a statistically significant association of OS with the metastatic pattern, the risk of death increasing by 2.5 and 12.4 times for patients with bilobar liver metastases and extra-abdominal lesions when compared with those with unilobar liver involvement ( $p=0.01$ and $p<0.0001$, respectively). We presented similar results in our study and confirmed a better prognosis in patients with unilobar hepatic tumour burden.

There are some limitations to our study. Due to its retrospective nature, there may have been some variation in the methods used to collect data over time and in the methodology used in the different participating centres. Normal ranges for laboratory values and the assays used vary, for example, for CgA. There is also, as with most retrospective analyses, the lack of a control-group and the possibility of selection bias with regard to the status of the participating hospitals as tertiary referral centres. Lastly, the number of missing data (especially with regard to laboratory values) made meaningful multivariate analyses impossible, since these analyses are much more sensitive to missing data than are univariate analyses. Therefore, most of our results have not been validated in a multivariate setting.

However, there are very limited published data from multicentre studies on prognostic factors in metastatic pNET patients. Our study reflects the real-life situation of a rare disease over a period of nearly 2 decades.

\section{Conclusion}

Retrospective univariate analyses of a defined set of variables in a subgroup of well-differentiated pNET patients showed some statistically significant correlations with prognosis. Although most prognostic markers were not found to be independent predictors of survival on the multivariate analysis, they showed a tendency in that direction. It is possible that these outcomes were affected, at least in part, by obvious laboratory data constraints, by the retrospective nature of our study, and by the size of the patient population. Further prospective studies in- 
volving a larger patient cohort may help clarify this issue. In the future, the variables employed here could provide a prognostic score for therapeutic stratification of this subgroup of pNETs.

\section{Acknowledgements}

Knowledge Network is sponsored by Ipsen UK. Editorial assistance was provided by Dr. Scott Gouveia of Solaris Health, and this study was funded by Ipsen.

\section{References}

1 Franko J, Feng W, Yip L, Genovese E, Moser AJ: Non-functional neuroendocrine carcinoma of the pancreas: incidence, tumor biology, and outcomes in 2,158 patients. J Gastrointest Surg 2010;14:541-548.

2 Fraenkel M, Kim MK, Faggiano A, Valk GD: Epidemiology of gastroenteropancreatic neuroendocrine tumours. Best Pract Res Clin Gastroenterol 2012;26:691-703.

3 Rindi G, Falconi M, Klersy C, Albarello L, Boninsegna L, Buchler MW, Capella C, Caplin M, Couvelard A, Doglioni C, et al: TNM staging of neoplasms of the endocrine pancreas: results from a large international cohort study. J Natl Cancer Inst 2012;104:764-777.

4 Folkert IW, Hernandez P, Roses RE: Multidisciplinary management of nonfunctional neuroendocrine tumor of the pancreas. World J Gastroenterol 2016;22:3105-3116.

5 Halfdanarson TR, Rabe KG, Rubin J, Petersen GM: Pancreatic neuroendocrine tumors (PNETs): incidence, prognosis and recent trend toward improved survival. Ann Oncol 2008;19:1727-1733.

6 Jensen RT, Berna MJ, Bingham DB, Norton JA: Inherited pancreatic endocrine tumor syndromes: advances in molecular pathogenesis, diagnosis, management, and controversies. Cancer 2008;113(7 suppl):1807-1843.

7 Pavel M, O’Toole D, Costa F, Capdevila J, Gross D, Kianmanesh R, Krenning E, Knigge U, Salazar R, Pape UF, et al: ENETS consensus guidelines update for the management of distant metastatic disease of intestinal, pancreatic, bronchial neuroendocrine neoplasms (NEN) and NEN of unknown primary site. Neuroendocrinology 2016;103:172-185.

8 Falconi M, Bartsch DK, Eriksson B, Kloppel G, Lopes JM, O'Connor JM, Salazar R, Taal BG, Vullierme MP, O’Toole D, et al: ENETS Consensus Guidelines for the management of patients with digestive neuroendocrine neoplasms of the digestive system: well-differentiated pancreatic non-functioning tumors. Neuroendocrinology 2012;95:120-134.

9 Falconi M, Eriksson B, Kaltsas G, Bartsch DK, Capdevila J, Caplin M, Kos-Kudla B, Kwekkeboom D, Rindi G, Kloppel G, et al: ENETS consensus guidelines update for the management of patients with functional pancreatic neuroendocrine tumors and non-functional pancreatic neuroendocrine tumors. Neuroendocrinology 2016;103:153-171.

10 Tamagno G, Sheahan K, Skehan SJ, Geoghegan JG, Fennelly D, Collins CD, Maguire D, Traynor O, Brophy DP, Cantwell C, et al: Ini- tial impact of a systematic multidisciplinary approach on the management of patients with gastroenteropancreatic neuroendocrine tumor. Endocrine 2013;44:504-509.

11 Mauriello C, Napolitano S, Gambardella C, Candela G, De Vita F, Orditura M, Sciascia V, Tartaglia E, Lanza M, Santini L, et al: Conservative management and parenchyma-sparing resections of pancreatic neuroendocrine tumors: literature review. Int J Surg 2015; 21(suppl 1):S10-S14.

12 Sallinen V, Haglund C, Seppanen H: Outcomes of resected nonfunctional pancreatic neuroendocrine tumors: do size and symptoms matter? Surgery 2015;158:1556-1563.

13 Ye L, Ye H, Zhou Q, Li Z, Lin Q, Tan L, Gao W, Fu Z, Zheng S, Chen R: A retrospective cohort study of pancreatic neuroendocrine tumors at single institution over 15 years: New proposal for low- and high-grade groups, validation of a nomogram for prognosis, and novel follow-up strategy for liver metastases. Int J Surg 2016;29:108-117.

14 Shanahan MA, Salem A, Fisher A, Cho CS, Leverson G, Winslow ER, Weber SM: Chromogranin A predicts survival for resected pancreatic neuroendocrine tumors. J Surg Res 2016;201:38-43.

15 Han X, Zhang C, Tang M, Xu X, Liu L, Ji Y, Pan $B$, Lou $W$ : The value of serum chromogranin A as a predictor of tumor burden, therapeutic response, and nomogram-based survival in wellmoderate nonfunctional pancreatic neuroendocrine tumors with liver metastases. Eur J Gastroenterol Hepatol 2015;27:527-535.

16 Strosberg JR, Cheema A, Weber J, Han G, Coppola D, Kvols LK: Prognostic validity of a novel American joint committee on cancer staging classification for pancreatic neuroendocrine tumors. J Clin Oncol 2011;29:3044-3049.

17 Cho JH, Ryu JK, Song SY, Hwang JH, Lee DK, Woo SM, Joo YE, Jeong S, Lee SO, Park BK, et al: Prognostic validity of the American joint committee on cancer and the European neuroendocrine tumors staging classifications for pancreatic neuroendocrine tumors: a retrospective nationwide multicenter study in South Korea. Pancreas 2016;45:941-946.

18 Russolillo N, Vigano L, Razzore P, Langella S, Motta M, Bertuzzo F, Papotti M, Ferrero A: Survival prognostic factors of gastro-entericpancreatic neuroendocrine tumors after primary tumor resection in a single tertiary center: comparison of gastro-enteric and pancreatic locations. Eur J Surg Oncol 2015;41: 751-757.
19 Boyar Cetinkaya R, Vatn M, Aabakken L, Bergestuen DS, Thiis-Evensen E: Survival and prognostic factors in well-differentiated pancreatic neuroendocrine tumors. Scand J Gastroenterol 2014;49:734-741.

20 Modlin IM, Lye KD, Kidd M: A 5-decade analysis of 13,715 carcinoid tumors. Cancer 2003;97:934-959.

21 Gustafsson BI, Kidd M, Modlin IM: Neuroendocrine tumors of the diffuse neuroendocrine system. Curr Opin Oncol 2008;20:1-12.

22 Rindi G, Kloppel G, Alhman H, Caplin M, Couvelard A, de Herder WW, Erikssson B, Falchetti A, Falconi M, Komminoth P, et al: TNM staging of foregut (neuro)endocrine tumors: a consensus proposal including a grading system. Virchows Archiv 2006;449:395401.

23 Rindi G, Kloppel G, Couvelard A, Komminoth P, Korner M, Lopes JM, McNicol AM, Nilsson O, Perren A, Scarpa A, et al: TNM staging of midgut and hindgut (neuro) endocrine tumors: a consensus proposal including a grading system. Virchows Archiv 2007;451: 757-762.

24 Pape U-F, Jann H, Müller-Nordhorn J, Bockelbrink A, Berndt U, Willich SN, Koch M, Röcken C, Rindi G, Wiedenmann B: Prognostic relevance of a novel TNM classification system for upper gastroenteropancreatic neuroendocrine tumors. Cancer 2008;113:256265.

25 Edge SB, Byrd DR, Compton CC, Fritz AG, Greene FL, Trotti A: AJCC Cancer Staging Manual (ed 7). New York, Springer, 2010.

26 Bosman F, Carneiro F: World Health Organization Classification of Tumours, Pathology and Genetics of Tumours of the Digestive System. Lyon, IARC Press, 2010.

27 Jann H, Roll S, Couvelard A, Hentic O, Pavel M, Müller-Nordhorn J, Koch M, Röcken C, Rindi G, Ruszniewski P, et al: Neuroendocrine tumors of midgut and hindgut origin: Tumor-node-metastasis classification determines clinical outcome. Cancer 2011;117: 3332-3341.

28 Rindi G, Falconi M, Klersy C, Albarello L, Boninsegna L, Buchler MW, Capella C, Caplin M, Couvelard A, Doglioni C, et al: TNM staging of neoplasms of the endocrine pancreas: results from a large international cohort study. J Natl Cancer Inst 2012;104:764-777.

29 Ambrosini V, Tomassetti P, Franchi R, Fanti S: Imaging of NETs with PET radiopharmaceuticals. Q J Nucl Med Mol Imaging 2010;54: $16-23$. 
30 Oken MM, Creech RH, Tormey DC, Horton J, Davis TE, McFadden ET, Carbone PP: Toxicity and response criteria of the Eastern Cooperative Oncology Group. Am J Clin Oncol 1982;5:649-656.

31 Ahmadzadehfar H, Biersack HJ, Ezziddin S: Radioembolization of liver tumors with yttrium-90 microspheres. Semin Nucl Med 2010;40:105-121.

32 Doerffel Y, Wermke W: Neuroendocrine tumors: characterization with contrast-enhanced ultrasonography. Ultraschall Med 2008;29:506-514.

33 Toumpanakis C, Meyer T, Caplin ME: Cytotoxic treatment including embolization/chemoembolization for neuroendocrine tumours. Best Pract Res Clin Endocrinol Metabol 2007;21:131-144.

34 Ezziddin S, Adler L, Sabet A, Pöppel TD, Grabellus F, Yüce A, Fischer HP, Simon B, Höller T, Biersack HJ, et al: Prognostic stratification of metastatic gastroenteropancreatic neuroendocrine neoplasms by 18F-FDG PET: feasibility of a metabolic grading system. J Nucl Med 2014;55:1260-1266.

35 Pavel M, Jann H, Prasad V, Drozdov I, Modlin IM, Kidd M: NET blood transcript analysis defines the crossing of the clinical rubicon: when stable disease becomes progressive. Neuroendocrinology 2017;104:170-182.

36 Modlin IM, Bodei L, Kidd M: Neuroendocrine tumor biomarkers: From monoanalytes to transcripts and algorithms. Best Pract Res Clin Endocrinol Metab 2016;30:59-77.

37 Panzuto F, Boninsegna L, Fazio N, Campana D, Pia Brizzi M, Capurso G, Scarpa A, De Braud F, Dogliotti L, Tomassetti P, et al: Metastatic and locally advanced pancreatic endocrine carcinomas: analysis of factors associated with disease progression. J Clin Oncol 2011;29:2372-2377.

38 Scarpa A, Mantovani W, Capelli P, Beghelli S, Boninsegna L, Bettini R, Panzuto F, Pederzoli P, delle Fave G, Falconi M: Pancreatic endocrine tumors: improved TNM staging and histopathological grading permit a clinically efficient prognostic stratification of patients. Mod Pathol 2010;23:824-833.

39 Jann H, Denecke T, Koch M, Pape UF, Wiedenmann B, Pavel M: Impact of octreotide long-acting release on tumour growth control as a first-line treatment in neuroendocrine tumours of pancreatic origin. Neuroendocrinology 2013;98:137-143.

40 Panzuto F, Boninsegna L, Fazio N, Campana D, Pia Brizzi M, Capurso G, Scarpa A, De Braud F, Dogliotti L, Tomassetti P, et al: Metastatic and locally advanced pancreatic endocrine carcinomas: analysis of factors associated with disease progression. J Clin Oncol 2011;29:2372-2377.

41 Scarpa A, Mantovani W, Capelli P, Beghelli S, Boninsegna L, Bettini R, Panzuto F, Pederzoli P, Fave Gd, Falconi M: Pancreatic endocrine tumors: improved TNM staging and histopathological grading permit a clinically efficient prognostic stratification of patients. Mod Pathol 2010;23:824-833.

42 O'Toole D, Couvelard A, Rebours V, Zappa M, Hentic O, Hammel P, Levy P, Bedossa P, Raymond E, Ruszniewski P: Molecular markers associated with response to chemotherapy in gastro-entero-pancreatic neuroendocrine tumors. Endocr Relat Cancer 2010;17:847856.

43 Sorbye H, Welin S, Langer SW, Vestermark LW, Holt N, Osterlund P, Dueland S, Hofsli E, Guren MG, Ohrling K, et al: Predictive and prognostic factors for treatment and survival in 305 patients with advanced gastrointestinal neuroendocrine carcinoma (WHO G3): the NORDIC NEC study. Ann Oncol 2013;24: 152-160.

44 Caplin ME, Pavel M, Ćwikła JB, Phan AT, Raderer M, Sedláčková E, Cadiot G, Wolin EM, Capdevila J, Wall L, et al: Lanreotide in metastatic enteropancreatic neuroendocrine tumors. N Engl J Med 2014;371:224-233.

45 Dilz LM, Denecke T, Steffen IG, Prasad V, von Weikersthal LF, Pape UF, Wiedenmann
B, Pavel M: Streptozocin/5-fluorouracil chemotherapy is associated with durable response in patients with advanced pancreatic neuroendocrine tumours. Eur J Cancer 2015; 51:1253-1262.

46 Krug S, Boch M, Daniel H, Nimphius W, Müller D, Michl P, Rinke A, Gress TM: Streptozocin-based chemotherapy in patients with advanced neuroendocrine neoplasms - predictive and prognostic markers for treatment stratification. PLoS One 2015; 10:e0143822.

47 Arnold R, Wilke A, Rinke A, Mayer C, Kann PH, Klose KJ, Scherag A, Hahmann M, Müller $\mathrm{HH}$, Barth P: Plasma chromogranin A as marker for survival in patients with metastatic endocrine gastroenteropancreatic tumors. Clin Gastroenterol Hepatol 2008;6:820-827.

48 Clancy TE, Sengupta TP, Paulus J, Ahmed F, Duh MS, Kulke MH: Alkaline phosphatase predicts survival in patients with metastatic neuroendocrine tumors. Dig Dis Sci 2006;51: 877-884.

49 Rinke A, Müller H-H, Schade-Brittinger C, Klose KJ, Barth P, Wied M, Mayer C, Aminossadati B, Pape U-F, Bläker M, et al: Placebocontrolled, double-blind, prospective, randomized study on the effect of octreotide LAR in the control of tumor growth in patients with metastatic neuroendocrine midgut tumors: a report from the PROMID study group. J Clin Oncol 2009;27:4656-4663.

50 Panzuto F, Merola E, Rinzivillo M, Partelli S, Campana D, Iannicelli E, Pilozzi E, Mercantini P, Rossi M, Capurso G, et al: Advanced digestive neuroendocrine tumors: metastatic pattern is an independent factor affecting clinical outcome. Pancreas 2014; 43:212-218.

51 Partelli S, Inama M, Rinke A, Begum N, Valente R, Fendrich V, Tamburrino D, Keck T, Caplin ME, Bartsch D, et al: Long-term outcomes of surgical management of pancreatic neuroendocrine tumors with synchronous liver metastases. Neuroendocrinology 2015; 102:68-76 